\title{
Analisis Faktor-Faktor Yang Mempengaruhi Pengembalian Pinjaman Bmt Di Kecamatan Ngaglik Tahun 2012
}

\section{Unggul Priyadi*}

Abstract

This study aims to determine the profile of debtors and to analyze the changes of the variables 'that-affect the probability of loan repayment by the customer.

The data are obtained from questionnaires which distribute to four BMTs in Ngaglik namely BMT Al-Ikhwan, BMT Agawe Makmur, and BMT Partner Ummah Welfare.

Logistic regression Hosmer and Lemeshow Goodness value-OffFit Test and R2 Kerke Nagel concluded that the income variable has a positive and significant effect, the variable of interest has a negative influence, the kind of work has a positive impact, and general customer District of BMT Ngaglik has a good chance against repayment of BMT. Keywords: BMT, Loan, Logistic Regression, Sharia.

\section{Pendahuluan}

Baitul Maal wa Tanwil (BMT) merupakan organisasi bisnis yang juga berperan secara sosial. Sebagai lembaga bisnis, BMT lebih mengembangkan usahanya pada sektor keuangan, yakni simpanpinjam. Usaha ini seperti usaha lembaga perbankan syariah lainnya yakni menghimpun dana anggota (nasabah) serta menyalurkannya kepada sektor ekonomi yang halal dan menguntungkan. BMT sebagai lembaga sosial, memiliki kesamaan fungsi dan peran dengan lembaga amil zakat (LAZ). Untuk lembaga keuangan-mikro lainnya selain BMT umumnya lebih berorentasi bisnis. Oleh karena itu, BMT harus didorong agar

*Dosen Fakultas Ekonomi UII 
mampu berperan secara profesional menjadi LAZ yang mapan.

Bertambahnya usaha mikro akan mendorong semakin banyak pengusaha-pengusaha baru yang membutuhkan permodalan, ibarat menanam sebuah pohon maka kebutuan pupuk menjadi modal bagi tanaman. Maka pengusaha yang ingin cepat memberdayakan usaha yang sedang dibinanya membutuhkan modal yang cukup. Oleh karenanya banyak lembaga keuangan yang memfasilitasi hal tersebut. Namun demikian sering terjadi adanya kesulitan nasabah dalam akses sumber dana ke lembaga keuangan formal yang terkesan ribet. BMT memberikan solusi bagi masyarakat untuk mendapatkan dana dengan mudah dan cepat, terhindar dari jerat rentenir, dan mengacu pada prinsip syariah (Haryani,2010).

Untuk menentukan keberhasilan suatu BMT bukan hanya mengetahui banyaknya kredit yang diambil oleh nasabah. Program perkreditan tidak akan berarti apabila ternyata pengembaliannya macet. Dengan kemacetan pengembalian kredit, akan berpengaruh buruk pada program perkreditan selanjutnya (Renggaini,1999).

\section{Landasan Teori: Permintaan dan Penawaran Kredit}

Penawaran komoditas barang dan jasa adalah jumlah dari komoditas yang ditawarkan produsen kepada konsumen dalam pasar dengan tingkat harga dan jangka waktu tertentu. Sumber penawaran meliputi produksi pada waktu tertentu dengan persediaan pada waktu sebelumnya. Demikian halnya penawaran kredit, jika modal yang dimiliki oleh suatu bank meningkat maka jumlah kredit yang ditawarkan akan semakin meningkat juga. Pada kondisi ini menggunakan teori penawaran cateris paribus, yaitu variabel lain dianggap konstan atau tetap. (Triwibowo, 2009:34). Faktor-faktor penyaluran (L) atau penawaran kredit dipengaruhi oleh resiko kredit (R), modal bank (K), jumlah agunan $-1762$ 
(A), kondisi keuangan debitur (CF), kebijakan moneter (MP), dan adverse selection Sehingga hubungan tersebut dapat diperlihatkan sebagai berikut (Agung et al dalam Triwibowo, 2009):

$L=f(R, K, A, C F, M P$

Dalam resiko kredit mengandung asymmetric information dan moral hazard. asymmetric information yang merupakan faktor yang harus dihadapi oleh perbankan, karena bank tidak mengetahui kondisi yang sebenarnya terjadi pada perusahaan dalam melakukan aplikasi kredit. Kondisi tesebut akan menimbulkan terjadinya moral hazard dengan pihak peminjam yang tidak memiliki kemampuan yang baik dalam mengembalikan pinjaman yang diberikan oleh bank. Resiko kredit ini memiliki hubungan negatif, ketika resiko kredit meningkat maka akan menurunkan penawaran kredit. Modal bank memiliki pengaruh positif terhadap penawaran kredit. Hal ini disebabkan oleh kondisi likuiditas bank ditentukan dalam kemampuan bank untuk menyalurkan kredit, sebab kredit merupakan bagian dari aset bank. Agunan merupakan suatu bentuk komitmen dari debitur berupa suatu penjaminan aset yang dimilikinya kepada pihak bank dalam menyalurkan kredit. Agunan memiliki hubungan negatif dengan penawaran kredit. Kondisi keuangan debitur memiliki hubungan positif terhadap penawaran kredit, jika kondisi keuangan debitur baik maka penawaran kredit akan meningkat.

Dalam upaya mempengaruhi besar kecilnya penawaran kredit agar seusai dengan tujuan kebijakan ekonomi makro nasional maka Bank Indonesia (BI) dan pemerintah senantiasa mensinkronkan kebijakan fiskal dan moneter. BI dapat melakukan melalui kebijakan moneter dengan menggunakan instrumen berupa kebijakan pasar terbuka (Operasi Paar 
tebuka/OPT), kebijakan cadangan wajib minimum dan penentuan tingkat diskonto.

\section{Kajian Pustaka}

Jumhur (2006) melakukan kajian analisis terhadap Permintaan Kredit Modal Kerja Usaha Kecil di Kota Semarang (Studi Kasus Permintaan Modal Kerja Usaha Kecil Sektor Perdagangan dari BMT). Penelitian dilakukan terhadap 100 sampel pengusaha kecil sektor perdagangan, dengan menggunakan alat analisis Logit, diperoleh kesimpulan bahwa :

1. Secara keseluruhan model probabilitas permintaan kredit modal kerja usaha kecil yang diestimasi dengan model Regresi Logistik memberikan hasil yang baik dan perilaku empirik variabel yang diteliti sesuai dengan ekspektasi perilaku teoritis bila dilihat dari kesesuaian tanda pengaruh variabel independennya

2. Secara parsial pengaruh jumlah asset, makin tinggi yang dimiliki usaha kecil sektor perdagangan maka keperluan terhadap modal kerja juga semakin meningkat, demikian halnya keuntungan per bulan yang diperoleh usaha kecil sektor perdagangan berpengaruh positif terhadap permintaan modal kerja usaha kecil, tetapi tidak signifikan terhadap probabilitas permintaan modal kerja dari BMT. Sedangkan rasio bagi hasil yang diterapkan oleh BMT berpengaruh negatif terhadap probabilita usaha kecil meminjam modal kerja dari BMT. Hal ini disebabkan rasio bagi hasil merupakan biaya penggunaan dana oleh nasabah peminjam yang harus dikembalikan ke BMT.

Penelitian oleh Alla Asmara (Staf Pengajar Departemen Ilmu Ekonomi, FE dan Manajemen IPB) yang menganalisis Tingkat Pengembalian Pinjaman Dana Ekonomi Produktif Masyarakat dan peran Lembaga Keuangan pada Program Pemberdayaan Ekonomi 1764 
Masyarakat Pesisir di Kabupaten Indramayu. Dalam penelitian studi kasus tersebut, pengumpulan data dilakukan dengan metode survei yang bersifat eksploratif. Dalam penelitian tersebut variabel jumlah pinjaman berpengaruh positif terhadap besarnya nilai tunggakan dengan koefisien regresi sebesar 0,752. Nilai tersebut berarti bahwa setiap satu persen peningkatan jumlah pinjaman menyebabkan kenaikan jumlah tunggakan sebesar 0,752 persen (cateris paribus).

\section{Metode Penelitian}

Alat analisis yang akan digunakan dalam adalah peluang logistik . Model logit adalah model regresi non-linear yang menghasilkan sebuah persamaan dimana variabel dependen bersifat kategorikal. Kategori paling dasar dari model tersebut menghasilkan binary values seperti angka 0 dan 1. Angka yang dihasilkan mewakilkan suatu kategori tertentu yang dihasilkan dari perhitungan probabilitas terjadi kategori tersebut (Hosmer, 1989).

Kuncoro (2001), logistic regression tidak memiliki asumsi nommalitas atas variabel bebas yang digunakan dalam model. Artinya, variabel penjelas tidak harus terdistribusi normal. Sejalan dengan hal tersebut, Ghozali (2006) menyatakan pengujian multivariat dengan binary logistic regression tidak memerlukan uji normalitas atas variabel bebas yang digunakan dalam model, artinya variabel penjelas tidak harus memiliki distribusi normal, linear, maupun memiliki varian yang sama dalam setiap grup. Hal ini disebabkan oleh teknik estimasi variabel dependen yang melandasi logistic regression adalah maximum likelihoodbukan asumsi Ordinary Least Square (OLS). Pengujian hipotesis yaitu analisis multivariat menggunakan regresi logistik (logistic regression) dengan tahapan sebagai berikut (Ghozali, 2009): 


\section{Menilai Keseluruhan Model (Overall Model Fit)}

Pengujian ini dilakukan untuk menilai model yang dihipoteiskan fit dengan data atau tidak. Pengujian dilakukan dengan membandingkan nilai antara -2 log likelihood pada awal (blok number $=0$ ) dengan nilai -2 log likelihood pada akhir (blok number $=1$ ). Pengurangan nilai antara $-2 L L$ awal (initial $-2 L L$ function) dengan nilai -2LL pada langkah awal berikutnya menunjukkan bahwa variabel yang dihipotesiskan fit dengan data. Untuk menguji kelayakan model peluang logistik ditentukan berdasarkan nilai dari Hosmer \& Lemeshow's Goodness of Fit Test. Jika nilai statistik Hosmer \& Lemeshow's Fit Test lebih besar dari 0,05 maka hipotesis nol tidak dapat ditolak yang berarti model mampu memprediksi nilai observasinya atau dapat dikatakan model dapat diterima karena sesuai dengan data observasinya. Pengujian ini sama seperti dalam regresi berganda menilai Koefisien Determinasi $\left(\mathrm{R}^{2}\right)$, yang menyatakan seberapa besar kombinasi variabel independen mampu menjelaskan variasi variabel dependen. Formulasi pengambilan keputusan adalah jika probabilitas $>0,05$ maka Ho diterima dan sebaliknya jika probabilitas $<0,05$ Ho ditolak

2. Koefisien Regresi Logistik

$\because \quad$ Pengujian ini dilakukan untuk mengetahui apakah masingmasing variabel independen berpengaruh terhadap variabel dependen dengan menggunakan Wald statistic dan nilai probabilitas.Wald statistic memberikan tingkat signifikansi secara statistik untuk masing-masing koefisien. Nilai Wald statistic dibandingkan dengan tabel X2, sedangkan nilai probabilitas dibandingkan dengan $\alpha(5 \%)$. Penentuan penerimaan atau penolakan $\mathrm{H}_{0}$ didasarkan pada tingkat signifikansi $\alpha(5 \%)$ dengan kriteria sebagai berikut : 
a. $\mathrm{H}_{0}$ tidak dapat ditolak apabila statistik Wald hitung $<$ Chi Square tabel dan nilai probabilitas (sig) $>$ tingkat signifikansi (a) $5 \%$. Hal ini berarti $\mathrm{H}_{\mathrm{a}}$ ditolak atau hipotesis yang menyatakan variabel independen berpengaruh terhadap variabel dependen ditolak.

b. Ho ditolak apabila statistik Wald hitung $>$ Chi Square table dan nilai probabilitas (sig) < tingkat signifikansi (a) $5 \%$. Hal ini berarti Ha diterima atau hipotesis yang menyatakan variabel independen berpengaruh terhadap variabel dependen diterima.

\section{Estimasi Parameter}

Pengujian ini dilakukan untuk mengetahui pengaruh antara odds dan variabel bebas. Estimasi maksimum likelihood parameter dari model ditunjukkan pada tampilan output variable in the equation. Model analisis logit yang digunakan dalam metode maximum likelihood, dinyatakan dalam persamaan :

$$
\operatorname{Ln} \frac{p}{1-p}=b 0+b 1 X 1+b 2 X 2+b 3 X 3+B 4 X 4 \ldots \ldots+b k X k
$$

Dimana :

$\mathbf{P}=$ Probabilitas pengembalian Pinjaman Kredit, $X_{1}=$ Pendapatan per bulan (Rp/bulan), $X_{2}=$ Bunga Bank Lain (\% (Rp) / bulan), $X_{3}=$ Tingkat Pendidikan (tahun), $X_{4}=$ Besarnya Pinjaman (Rp), $X_{5}=$ Jenis Pekerjaan (var. dummy), $0=$ pekerjaan tetap, $1=$ pekerjaan tidak tetap, $P$, adalah probabilitas kembalinya pinjaman kredit sedangkan $\mathrm{X}_{1}, \mathrm{X}_{2}, \ldots \ldots \ldots \mathrm{X}_{\mathrm{k}}$ adalah variabel independennya. In (Odds) adalah probabilitas yang sering dinyatakan dalam istilah odds. 


\section{Hasil Analisis}

1.Pengujian hasil nilai Hosmer dan Lemeshow Goodness-Off-Fit Test

\section{Tabel 1: Hosmer dan Lemeshow Goodness-Off-Fit Test}

\begin{tabular}{|c|c|c|c|c|}
\hline & \multicolumn{4}{|c|}{ Hosmer and Lemeshow Test } \\
\hline & Step & Chi-square & df & Sig. \\
\hline 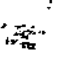 & 1 & 2.816 & 8 & .945 \\
\hline
\end{tabular}

Model fit diuji dengan Hosmer and Lemeshow's goodness of fit yang menguji hipotesis nol bahwa data empiris cocok atau sesuai dengan model. jika nilai Hosmer and Lemeshow's signifikan atau lebih kecil dari 0,05 maka hipotesis nol ditolak dan model dikatakan tidak fit. Sebaliknya jika tidak signifikan maka hipotesis nol tidak dapat ditolak yang berarti data empiris sama dengan model atau model dikatakan fit. Dari hasil penelitian menunjukan nilai Hosmer and Lemeshow's sebesar 1.893 dan signifikan pada 0.984 oleh karena nilai ini diatas $\mathbf{0 . 0 5}$ maka model dikatakan fit dan model dapat diterima.

\section{Pengujian Nagel Kerke ${ }^{2}$}

$\therefore$ Pengujian ini dilakukan untuk mengetahui besarnya sumbangan atau' kontribusi pengaruh dari variabel independen terhadap dependen nya dapat ditunjukkan dengan nilai Nagel KerkeR ${ }^{2}$. Hasil pengujian model ini adalah sebagai berikut:

Tabel 2: Nilai Nagel KerkeR

\begin{tabular}{|c|c|l|l|}
\hline Step & $\begin{array}{c}-2 \text { Log } \\
\text { likelihood }\end{array}$ & $\begin{array}{l}\text { Cox \& Snell R } \\
\text { Square }\end{array}$ & $\begin{array}{l}\text { Nagelkerke R } \\
\text { Square }\end{array}$ \\
\hline 1 & $8.729^{\mathrm{a}}$ & .265 & 847 \\
\hline
\end{tabular}

Sumber : data primer diolah kembali, 2012 
Nilai Cox dan Snell's R Square dan Nagelkerke's R dapat digunakan untuk menilai model fit. Nilai Cox and Snell's sebesar 0,265 dan Nilai Nagelkerke's $R$ pada tabel adalah 0,847 . Hal ini berarti variabilitas ke lima variabel independen sebesar 84,7 persen sedangkan sisanya 25,3 persen dijelaskanoleh variabel-variabel lain di luar model penelitian.

\section{Hasil Uji Koefisien Regresi Logistik}

Analisis regresi logistik digunakan untuk mengetahui pengaruh independent variable yaitu : pendapatan, bunga, tingkat pendidikan, besarnya pinjaman, dan jenis pekerjaan terhadap dependent variable yaitu : peluang pengembalian pinjaman BMT di Kecamatan Ngaglik. Berikut ini adalah hasil pengolahan data dengan menggunakan SPSS.

Tabel 3: Hasil Uji Koefisien Regresi Logistik Variables in the Equation

\begin{tabular}{|l|r|r|r|r|r|r|}
\hline & \multicolumn{1}{|c|}{ B } & \multicolumn{1}{|c|}{ S.E. } & \multicolumn{1}{c|}{ Wald } & df & Sig. & $\operatorname{Exp(B)}$ \\
\hline X1_pendapatan & .293 & .122 & 5.718 & 1 & .017 & .746 \\
X2_bunga & -1.112 & .823 & 1.824 & 1 & .047 & .329 \\
X3_tingkat pendidikan & .129 & .094 & 1.881 & 1 & .170 & 1.138 \\
X4_jumlah pinjaman & -.001 & -.004 & -.050 & 1 & .022 & 1.001 \\
\hline X5_jenis pekerjaan (0= & & & & & & \\
pekejaan tidak tetap, & -7.536 & 32.396 & .054 & 1 & .081 & .001 \\
1= pekerjaan tetap) & & & & & & \\
Constant & 50.880 & 40.447 & 1.582 & 1 & .208 & 0.0125 \\
\hline
\end{tabular}


$\operatorname{Ln} \mathrm{p} /(1-\mathrm{p})=50.880+0.293(\mathrm{X} 1)-1.112(\mathrm{X} 2)+0.129(\mathrm{X} 3)+$ $0.001(\mathrm{X} 4)-7.536(\mathrm{X} 5)$

Persamaan di atas menunjukan bahwa variabel-variabel yang berpengaruh secara signifikan terhadap peluang pengembalian kredit dapat dijelaskan sebagai berikut :

Pengaruh pendapatan $\left(\mathrm{X}_{1}\right)$ terhadap peluang pengembalian pinjaman BMT di Ngaglik memiliki nilai koefisien regresi positif sebesar 0,293 dengan tingkat signifikansi sebesar0,017 yang lebih kecil dari 0,05 . Hal ini berarti frekuensi pendapatan berpengaruh signifikan terhadap peluang pengembalian pinjaman. Tingkat pendidikan tidak berpengaruh secara signifikan terhadap peluang pengembalian pinjaman. Pengaruh suku bunga $\left(\mathrm{X}_{2}\right)$ terhadap peluang pengembalian pinjaman BMT menunjukkan nilai koefisien regresi negatif sebesar 1.112 dengan tingkat signifikansi sebesar 0,047 (lebih kecil dari 0,05), artinya berarti tingkat suku bunga secara signifikan berpengaruh negatif terhadap peluang pengembalian pinjaman BMT.

Untuk variabel $\mathrm{X}_{4}$ (jumlah pinjaman) menunjukan nilai koefisien regresi 0,001 dengan tingkat signifikansi sebesar 0,022 lebih kecil dari $\alpha=0,05$. Hal ini berarti jumlah pinjaman berpengaruh signifikan terhadap peluang pengembalian pinjaman. Pengaruh jenis pekerjaan (X5) terhadap peluang pengembalian pinjaman BMT memiliki nilai koefisien regresi negatif $-7,536$ sebesar 0.293 dengan tingkat signifikansi sebesar 0,081 yang lebih besar dari 0,05 yang berarti tidak berpengaruh secara signifikan. Hal ini berarti jenis pekerjaan para responden yang dibedakan mempunyai pekerjaan tetap dan pekerjaan tidak tetap tidak berpengaruh secara signifikan terhadap peluang pengembalian pinjaman. Pembedaan jenis pekerjaan yang merupakan salah satu kriteria nasabah menjadi sesuatu yang tidak 1770 
penting dalam kasus pengembalian kredit BMT di Kecamatan Ngaglik. Hal ini menjadi berbeda dengan gejala yang umumnya terjadi yang biasanya dengan mengetahui pekerjaan nasabah maka pihak pemberi kredit dari lembaga keuangan (bank dan non bank) dapat mengetahui alokasi pendapatan untuk angsuran pinjaman yang diambil.

Demikian halnya pengaruh tingkat pendidikan (X3) terhadap peluang pengembalian pinjaman BMT di Ngaglik tidak berpengaruh secara signifikan. Variabel pendapatan memiliki nilai koefisien regresi positif sebesar 0.129 dengan tingkat signifikansi sebesar0,170 yang lebihbesar dari 0,05. Hal ini berarti frekuensi tingkat pendidikan secara parsial tidak berpengaruh signifikan terhadap peluang pengembalian pinjaman, berapapun lama nasabah menempuh jenjang pendidikan tidak akan menambah peluang pengembalian pinjaman. Untuk mengkaji lebih mendalam tentang pendidikan perlu dipertimbangkan faktor lain seperti pengkajian jenis pendidikan atas basis agama atau yang tidak berbasis agama, lokasi berada di perkotaan atau pedesaan serta berbagi pertimbangan faktor lain yang berpengaruh terhadap kualitas pendidikan.

Untuk menentukan besarnya pengaruh variabel independen terhadap peluang pengembalian pinjaman digunakan ilustrasi pada nilainilai variabel pada besaran mean, modus, nilai minimum dan nilai maksimum. Hasil perhitungan tersebut disajikan pada tabel berikut :

Tabel 4: Perhitungan Model Regresi Logistik

\begin{tabular}{|l|c|c|c|c|}
\hline & Mean & Modus & Min & Maks \\
\hline $\mathrm{X}_{1}$ (Pendapatan/Rp) & 474044.7 & 293000 & 175800 & 1025500 \\
\hline $\mathrm{X}_{2}$ (Bunga\% tahun) & 17.981 & 16.68 & 16.68 & 20.016 \\
\hline $\mathrm{X}_{4}$ (Jumlah Pinjaman / Rp ribuan) & 4012.791 & 1000 & 300 & 20000 \\
\hline $\begin{array}{c}\mathrm{X}_{5} \text { (Jenis Pekerjaan 0 = pekerjaan } \\
\text { tidak tetap, 1 = pekerjaan tetap) }\end{array}$ & 0.5193 & 0 & 0 & 1 \\
\hline
\end{tabular}




\begin{tabular}{|l|l|l|l|l|}
\hline Peluang Pengembalian Pinjaman (Y) & 0.7969 & 0.7142 & 0.4440 & 0.8955 \\
\hline
\end{tabular}

\section{Sumber : data primer diolah kembali,2012}

Untuk memaknai besaran peluang perhitungan fungsi logistik dalam penentuan peluang pengembalian pinjaman dengan penyederhanaan berbagai nilai menjadi 2 kategori yaitu jika peluang diatas nilai 0,5 berarti terdapat peluang pengembalian sedangkan jika nilai dibawah 0,5 bermakna sebaliknya. Ilustrasi diatas didasarkan nilai mean pendapatan nasabah BMT sebesar Rp 474.044,7, bunga pinjaman17,81 persen per tahun, jumlah pinjaman $\mathrm{Rp}$ 4,012.791 dengan pekerjaan nasabah sebagai pegawai tetap dan tidak tetap jumlahnya sama maka peluang pengembalian pinjaman oleh nasabah sebesar 0.79685 (lebih besar dari 0,5). Sedangkan jika nasabah mempunyai pekerjaan tetap dan variable lain mengambil nilai mean maka secara bersama-sama peluang pengembalian lebih nyata. Sementara jika nasabah pekerjaannya tidak tetap semua variable secara bersama-sama tidak mempunyai peluang untuk tidak mengembalikan kredit (peluang lebih kecil dari 0,5). Peluang pengembalian pinjaman di BMT selain terjadi terjadi pada saat variable berada pada nilai mean, pada ilustrasi nilai-nilai variable pada besaran modus, nilai maksimum juga memberikan ilustrai peluang pengembalian pinjamian.

Dari berbagai gambaran besamya nilai-nilai variabel (mean, modus, nilai maksimum dan minimum) maka hanya pada nilai-nilai variabel pada besaran yang minimum maka tidak terdapat peluang untuk mengembalikan pinjaman di BMT. Hal tersebut terjadi jika nasabah mempunyai pendapatan $\mathrm{Rp} 175.800$ dengan bunga sebesar 16.68 persen per tahun, jumlah pinjaman Rp 300.000, serta tidak mempunyai pekerjaan tetap mempunyai nilai peluangr 0.444037334 (nilai dibawah 0.5 ). 
Dengan demikian pengaruh dari variabel pendapatan, jenjang pendidikan semakin tinggi diikuti besarnya bagi hasil (bunga) yang semakin rendah serta, responden mempunyai pekerjaan tetap akan mendorong peluang penembalian pinjaman BMT di Kecamatan Ngaglik. Dengan mencermati faktor-faktor yang mendorong kelancaran pengembalian kredit maka dapat dijadikan referensi dan kajian untuk menciptakan peluang lancarnya pengembalian pinjaman yang pada akhirnya mendorong perputaran ekonomi semakin lancar.

\section{Kesimpulan}

Peluang pengembalian kredit di BMT Kecamatan Ngaglik secara bersama-sama dipengaruhi oleh pendapatan nasabah, bagi hasil (bunga bank), jenjang pendidikan, besarnya pinjaman dan jenis pekerjaan. Namun demikian secara parsial peluang pengembalian kredit di BMT tidak dipengaruhi oleh tingkat pendidikan dan jenis pekerjaan.

\section{Saran}

Berdasarkan hasil pembahasan dan kesimpulan di atas maka untuk mendorong peluang pengembalian kredit pada BMT di Kecamatan Ngalik, penyaluran kredit diberikan pada nasabah yang mempunyai pendapatan semakin besar, bagi hasil yang semakin rendah, pendidikan nasabah yang semakin tinggi, besaran pinjaman pada debitur pinjaman rendah serta nasabah yang mempunyai pekerjaan tidak tetap.

Untuk mengkaji lebih lanjut terhadap variabell pendidikan yang tidak berpengaruh secara signifikan serta jenis pekerjaan tidak tetap yang lebih mendorong peluang pengembalian kredit perlu diadakan penelitian lebih lanjut. 


\section{Implikasi}

Dengan diketahui dan dicermati faktor-faktor yang mendorong kelancaran pengembalian kredit maka dapat dijadikan referensi dan kajian untuk menciptakan peluang lancarnya pengembalian pinjaman kepada BMT khususnya yang berlokasi di Kecamatan Ngaglik. Apabila hal ini dapat terwujud maka tejadinya pengembalian kredit yang lancar pada akhirnya mendorong perputaran ekonomi yang semakin mendorong pembiayaan kegiatan ekonomi yang semakin baik. 
Unggul Priyadi, Analisis Faktor-faktor yang mempengaruhi.........

\section{Daftar Pustaka}

Al Qur'an Surah Al Baqarah ayat 278-279 \& Surah Al Imran ayat 130

David W.Hosmer and Stanley L (1989), Applied Logistic Regression. Singapore: Willey-Sons Interscience

Chaudhry , Muhammad Sharif. Dr, M.A., (2003) Sistem Ekonomi Islam, Jakarta: Kencana,

Ghozali, Imam, (2006), Analisis Multivariate Lanjutan Program SPSS.

Semarang: Badan Penerbit Universitas Diponegoro

Hasanudin. (2012) Perkembangan akad musyarakah, Jakarta: Kencana.

Muhammad Hanri, (2000), Sistem Peringatan metodologi, FE UI

Iswi haryani, (2010), Restrukturisasi dan Penghapusan Kredit Macet.

Jakarta: PT Elex Media Komputindo

Kasmir, (2002), Bank dan Lembaga Keuangan Lainnya. Jakarta: PT Raja

Grafindo Persada

Rahmawati dan Muid (2012) "Analisis Faktor-faktor Yang Berpengaruh

Terhadap Praktik Perataan”, Journal of Accounting Vol. 1. No

2,2012 .

Ridwan , Muhammad, (2008), Manajemen Baitul Mal., hal. 125,

Rowling, et al., (1998), Applied Regression Analysis: A-Research Tool,

Second Edition, Library Of Congress Cataloging, North

$\varsubsetneqq$ - California

Sugiyono, Metode Peneltian Kuantitaif Kualitatif dan R\&D, (2006), Bandung, ALFABETA

P3EI UII, Ekonomi Islam. Jakarta: Rajawali Pers,

Santoso Singgih, Mengatasi Berbagai Masalah Statistik dengan SPSS, PT Elex Media Komputindo,Jakarta, 2009

- Thahir Abdul Muhsin Sulaiman, Menanggulangi Krisis Ekonomi Secara Islam, Bandung: PT Alma'arif

Tempo,

(2012)

"Aset

BMT

TumbuhSignifikan",http://www.tempo.co/read/news/2012/11/07/0 89440268/Aset-BMT-Tumbuh-Signifikan

Utama Suyana. Statistika Ekonomi dan Bisnis.2009. Udayana University Press. Denpasar http://slemankab.go.id/wpcontent/file/rpjm/bab2.pdf

Binary Logistic Using SPSS. Diakses 20 Desember 2012 dari http://psychweb.psy.umt.edu/denis/datadecision/binary_logistic_s pss/index.html

Apa Itu regresi Stepwise??Diakses 10 Desember 2012 dari http://statisticsanalyst.wordpress.com/2009/08/18/apa-itu-regresistepwise/\#more-252 
hand out materi pelatihan analisis statistik untuk kesehatan diakses pada tanggal 20 Desember 2012 dari http://jingklak.wordpress.com/category/statistik/

Veitzal, H. Rivai dan Veitzal, Andria Permata, (2008), Islamic FinancialManagement. Jakarta: RajaGrafindo Persada

Vincent Gaspersz (1991), Ekonometrika Terapan. Bandung: TARSITO 